\title{
Taxonomia de la Producción Cinematográfica relacionada con la Educación
}

Taxonomy of Production Film related to Education

Eliana Novoa Ramírez 0000-0002-8116-6517

Universidad Jaime Bausate y Meza

enovoa@bausate.edu.pe
Recibido: 18/07/2021

Aprobado: 27/08/2021

Publicado: 15/09/2021

\section{Resumen}

El estudio propone un registro taxonómico de las principales producciones cinematográficas cuyas narrativas versan sobre la educación y sus actantes: alumnos, profesores, padres de familia, escuela y sociedad. El objetivo es seleccionar y clasificar la producción de películas de ficción cuyo discurso narrativo esté referido a la escuela. La metodología se fundamentó en el enfoque cualitativo descriptivo que utilizó la observación documental, la hermenéutica y el análisis crítico del mensaje audiovisual como técnicas de investigación. Como conclusión se estableció que existe una taxonomía de ocho clases de películas, atendiendo al específico tipo de conflicto principal que se anuda en la narrativa de cada filme.

Palabras clave: taxonomía; cine; conflicto dramático; educación.

\begin{abstract}
The study proposes a taxonomic record of the main cinematographic productions whose narratives are about education and its actants: students, teachers, parents, school and society. The objective is to select and classify the production of fiction films whose narrative discourse refers to the school. The methodology was based on the descriptive qualitative approach that used documentary observation, hermeneutics and critical análisis of the audiovisual message as research techniques. As a conclusion, it was established that there is a taxonomy of eight classes of films, attending to the specific type of main conflict that is knotted in the narrative of each film.
\end{abstract} 229

Keywords: taxonomy; cinema; dramatic conflict; education. 


\section{Introducción}

El cine, es fundamentalmente un medio que "representa la realidad, para verla y comprenderla" (Alves et all., 2018, p. 3). Desde su invención hasta la actualidad se han producido múltiples películas de diversos tipos y clases, y también se han elaborado múltiples estudios e investigaciones. En toda esta producción teórica existente son escasos las propuestas de orden y clasificación de estos estudios que permitan visibilizar y evaluar la evolución del estado del arte de los trabajos académicos en los que se relaciona el cine con la educación y la escuela. El marco epistémico que nos interesa delimitar es el objeto de estudio que comprende las películas cuyas narrativas se relacionan con la escuela y sus integrantes: alumnos, padres de familia, profesores, autoridades de la escuela y la sociedad.

Como antecedentes del presente estudio, destaca La educación cinematográfica de Peters (1961), que aborda la relación entre cine y educación, y propone despertar el interés por la educación cinematográfica de las autoridades de la enseñanza, maestros, padres de alumnos y, de manera general, de todos los que se preocupan de la influencia del cine en la juventud (p. 9).

En los estudios de Loscertales (1999) es donde se evidencia la primera selección de 44 películas centradas en la educación y la enseñanza; y 42 películas con personajes relacionados con la profesión docente (p. 39-43). Asimismo, Gómez (2005), analiza 15 filmes (producidos en los últimos 70 años), a los cuales denomina "películas de ambientaciones escolares", es decir aquellas películas que muestran el mundo de la escuela (p.4). Por otro lado, Picos (2014), aplica una encuesta a un grupo de 68 profesores de la Universidad Internacional de La Rioja (España), con el fin de identificar las películas sobre educación que ellos prefieren y recomiendan para desarrollar mentes críticas en los estudiantes. El resultado del estudio concluye con una propuesta de 89 películas, de las cuales las 5 primeras con mayor votación son: El club de los poetas muertos, La Ola, La clase, Profesor Holland y Los chicos del coro.

Sin embargo, lo que aún noexistees una clasificación que sustente una tipología cinematográfica que permita conocer cuáles son las específicas diferencias y semejanzas en las características de las narrativas de los filmes que tienen como protagonista la escuela. En este sentido, el objetivo del presente estudio es proponer una taxonomía que ordene, seleccione y clasifique las películas comerciales cuyos discursos narrativos estén referidos a los conflictos dramáticos que suceden en la escuela.

\section{Marco teórico}

\section{El cine como objeto de estudio}

Una película cinematográfica no solo es un medio de entretenimiento, es también un producto de la industria cultural (Horkheimer y Adorno, 1998), cargado de ideología (Althusser, 1974), una mercancía en el mercado de entretenimiento (Zillmann, 2000). En el contexto teórico del presente estudio, el cine es un objeto de estudio. Uno de los pioneros y el más importante difusor del Cine en la Educación es Martínez-Salanova (2003), quien propone: "Una película no basta con verla. Hay que analizarla con ojo crítico con el fin de sacarle todo el partido posible, para comprenderla mejor y valorar el cine como contador de historias, como transmisor de valores y como portador de arte y de conocimientos" (p. 46).

\section{La taxonomía}

El término proviene del griego taxis, que significa ordenación, distribución, clasificación; y nomia que significa norma, regla. Por lo tanto, taxonomía significa reglas o normas para ordenar una clasificación. Una de las primeras clasificaciones taxonómicas de los seres vivos lo realizó Aristóteles, identificando a más de quinientas especies animales, cuya división primaria es: animales con sangre (vertebrados) y los sin sangre (invertebrados). Este concepto de taxonomía fue retomado por Vigotsky y Bloom, en sus investigaciones y propuestas en la ciencias de la educación. En la producción de películas, la taxonomía se expresa mediante los géneros cinematográficos.

\section{Los géneros cinematográficos}

Al igual que Altman (2000), Fernández y López (2018), consideran que los géneros cinematográficos son una continuación del estudio de los géneros literarios, porque la literatura es base fundamental para el cine tomando forma específica en el propio guion cinematográfico, es así como los géneros de una película sirven para establecer 
su clasificación (comedia, drama, bélico, wéstern, musical, documental, terror, ciencia ficción, thriller negro y épico). (párr.1 y 4). Sin embargo, Altman complementa que los géneros cinematográficos han adquirido un corpus propio por las propuestas de los investigadores y críticos del cine, como consecuencia de la industria cinematográfica en un mercado global. (pp. 34-35). La determinación de los géneros cinematográficos constituye una matriz para ordenar la clasificación de los filmes. Altman (2000) y Zavala (2013) coinciden en que los géneros cinematográficos son fundamentales para atender las expectativas, preferencias y gustos del público. Para Guzmán (2013), la mercadotecnia que planifica y organiza el negocio del cine le interesa etiquetar el género o subgénero de las películas para facilitar el posicionamiento de un filme en el mercado cinematográfico (p. 90).

No obstante, en todas las tipologías de géneros cinematográficos existentes, aún no se han incluido el cine educativo, o la escuela en el cine, como género o subgénero, a pesar de que son numerosas las producciones que tratan esta temática. Una propuesta audaz es la de González y Valdés (2018), quienes proponen "la adolescencia como género cinematográfico" (p. 23).

\section{El conflicto cinematográfico}

Egri (2009), propone que el conflicto dramático se compone de la crisis, el clímax y la conclusión. El conflicto es una contradicción, un enfrentamiento entre intereses u objetivos distintos que expresan dos o más personajes que aspiran lograr objetivos contrarios.

El conflicto puede expresarse también entre todos los personajes enfrentados o resistiendo acontecimientos negativos que se suscitan en diferentes ambientes: contexto social, político y cultural. El conflicto puede surgir en cualquier escena del filme, incluso pueden expresarse múltiples conflictos, pero en la base de todo el discurso dramático está el conflicto principal, porque toda la trama gira en su entorno, desde el inicio hasta la final resolución. La expresión de un conflicto no implica necesariamente violencia física, esta puede ser psíquica, ideológica, pero siempre el conflicto es acción (Heil, 2011).

En el caso específico de las películas que versan sobre el tema de la escuela se ha identificado ocho distintos conflictos específicos que se expresan entre las fuerzas o voluntades opuestas, cuyos protagonistas son eventualmente seis: las autoridades de la escuela, los alumnos, los profesores, los padres de familia, el Estado y determinados acontecimientos contextuales.

\section{Metodología}

La presente investigación es de enfoque cualitativo, descriptivo e interpretativo (Hernández, et all., p.9). Se utilizó como técnicas de investigación para el recojo de la información la observación documental y la técnica del visionado de películas comerciales (Flick, 2007, pp. 169-170), así como el análisis crítico del mensaje audiovisual tal como lo plantean Diaz (2012, p. 194) y García (2015, pp. 109-111).

Estas técnicas de investigación permitieron seleccionar y clasificar un grupo de películas, producidas en distintos países, cuyos argumentos se refieren a la educación en las escuelas. Se conformó una muestra homogénea, no probabilística (Hernández et al., 2014, p. 182) de 21 películas y, con el análisis hermenéutico, a partir de los argumentos de la muestra, se identificaron los ocho tipos de conflictos dramáticos.

Adaptando el proceso metodológico de Denzin (1989, pp. 231-232), citado por Flick (2007), señalamos los cuatro pasos que propone para el análisis de las películas:

1. Las películas seleccionadas se consideraron como un todo: se registró la ficha técnica (director, año, país, actores, argumento).

2. Se seleccionaron y analizaron las escenas claves.

3. Se identificaron los 8 tipos de conflictos dramáticos en el argumento de las películas.

4. Se aplicó el análisis crítico del discurso audiovisual y se redactó una interpretación final (p. 170).

Finalmente, en base a este proceso metodológico, se estructuró la taxonomía en la cual fueron clasificadas las 21 películas, de acuerdo con los 8 tipos de conflictos dramáticos relacionados con la escuela. 


\section{Resultados}

A continuación, los ocho tipos de conflictos específicos sobre los cuales establecemos una clasificación de películas que versan sobre la escuela.

\section{Conflicto entre la escuela y alumnos}

Algunas realizaciones recurren a las contradicciones entre alumnos y autoridades del colegio como argumentos de sus películas. En este tipo de conflicto son memorables dos películas, cuyas historias transcurren en espacios cerrados (un internado laico y un colegio militar), recintos educativos en donde se impone una disciplina vertical y coercitiva, en base a la opresión y al castigo. Películas de este tipo son:

Cero en Conducta (1933), de Jean Vigo. El filme discurre a través de la historia de cuatro jóvenes estudiantes que, sujetos a un estricto régimen escolar represivo, deciden rebelarse contra la institución. En la ceremonia central del Aniversario de la Patria, organizada por el director de la escuela $\mathrm{y}$ ante las altas autoridades, los estudiantes realizan un acto de rebeldía y protesta que se expresa a través de la burla a la farsesca e hipócrita celebración de la festividad patriótica. Según Gubern (2014), el filme fue "una representación crítica y simbólica de los estamentos de la sociedad francesa, subrayando el lado grotesco de las jerarquías y de sus ridículas formas protocolarias" (p. 253).

La ciudad y los perros (1985) de Francisco Lombardi y adaptada de la novela homónima de Mario Vargas Llosa. La historia transcurre en el Colegio Militar de Lima, un internado en donde existe un permanente trato agresivo y humillante contra los estudiantes que ingresan. El conflicto principal se inicia cuando las autoridades del colegio expulsan a un estudiante del $5^{\circ}$ año por haber sustraído un día antes las preguntas de la prueba de un examen, y el conflicto entre los estudiantes se origina en saber qué alumno fue el delator, quien a su vez es asesinado en una campaña de práctica de tiro. El conflicto concluye cuando las autoridades quieren que este crimen sea visto ante la opinión pública como un accidente y de esta manera imponer su férrea autoridad contra los alumnos, enterrando en el olvido el homicidio.

\section{Conflicto entre alumnos y el profesor}

En este tipo de películas casi siempre es un profesor nuevo, sustituto, que viene de fuera del colegio y se incorpora a un grupo académico, en donde los alumnos son casi siempre rebeldes e indisciplinados, que agreden o se burlan del profesor, pero al final alumnos y profesor terminan reconociendo mutuamente sus nobles sentimientos. En esta línea están:

Mentes peligrosas (1995), de John N. Smith y protagonizada por Michelle Pfeiffer. Una profesora, con poca experiencia, es rechazada por un grupo de jóvenes rebeldes, afrodescendientes $\mathrm{y}$ latinos, provenientes de sectores marginales y segregados racialmente, que no les interesaba los estudios. Su formación en la marina y el dominio del karate atrae a sus alumnos y la enseñanza de la Literatura permite que paulatinamente se sensibilicen y exista un trato amical. Al final, el conflicto se resuelve cuando la profesora logra que los estudiantes se gradúen.

Al maestro con cariño (1967), de James Clavel y con la actuación de Sidney Poitier. Mark Thackeray es un ingeniero afrodescendiente sin empleo, que decide trabajar como docente en una escuela pública. El conflicto principal se da entre el profesor y los alumnos conflictivos, insolentes y groseros. Al principio el profesor intenta ganarse la aceptación y confianza de sus díscolos alumnos utilizando métodos tradicionales, pero fracasa y no tendrá más remedio que recurrir a ensayar otras fórmulas. La contradicción se resuelve cuando el profesor logra establecer una relación cordial y afectiva con los alumnos. En el filme destaca la canción que da título a la película To sir, with love, interpretada por la "alumna", la cantante Lulú.

Juego de honor (2005), de Thomas Carter y protagonizada por Samuel Jackson. El conflicto principal surge cuando un grupo de estudiantes adolescentes busca un entrenador para su equipo de baloncesto y consiguen a Ken Carter, quien descubre que los integrantes del equipo son jóvenes rebeldes y consumidores de drogas. Finalmente, el desenlace del conflicto principal se resuelve logrando que los jóvenes se tracen un futuro académico ingresando y posteriormente graduándose en la universidad. 


\section{Conflicto entre los alumnos}

Desde que un niño ingresa por primera vez en una escuela, esta vivencia casi siempre es traumática, porque ahora se encuentra desprotegido de la madre, se siente observado e intimidado por sus compañeros; $y$, si es agredido, su permanencia en la escuela se tornará insoportable y angustiante. Cuando son adolescentes surgen nuevos conflictos, perciben que entre ellos existen diferencias sociales, raciales y culturales, características que motivan sus conductas inestables, violentas y anárquicas, en donde los vínculos de amistad y lealtad son muy frágiles y efímeros. Películas de este tipo son:

El colegial (1927), de James Horne, con la actuación de Buster Keaton. Esta es considerada como la primera película cuyo argumento transcurre en la escuela. El conflicto principal se da en la rivalidad entre Ronald, un joven estudioso de familia modesta y Jeff, un compañero de clase y apuesto deportista, ambos pugnan por el amor de Mary, compañera de estudios. Estando en la universidad, Jeff ingresa al dormitorio de la chica en el internado y la fuerza a que sea su enamorada, ella se resiste y termina secuestrada; desesperada llama por teléfono a Ronald para que la libere, éste en un sorpresivo alarde deportivo va a salvarla, corre velozmente, elude obstáculos, con una pértiga logra ingresar por la ventana del segundo piso en donde está el cuarto de Mary, golpea al secuestrador y la rescata. El conflicto entre los estudiantes se disipa cuando Ronald y Mary se enamoran y se casan.

El joven Törless (1966), de Volker Schlöndorff, con la actuación de Mathieu Carrière y basada en la novela Las tribulaciones del joven Törless de Robert Musil. Törless es un adolescente en el internado de un opresivo colegio militar. Se hace amigo de dos estudiantes, quienes permanentemente agreden a Basini, un estudiante de origen judío que ha robado dinero a uno de ellos. Törless es testigo impasible de esta agresión, simplemente observa de manera imperturbable y neutral, no denuncia este abuso. Törless intenta darle una explicación racional al hecho, quiere saber hasta qué límites el ser humano es capaz de soportar tanta humillación. En las escenas finales del filme se resuelve el conflicto principal: Basini es expulsado del colegio y Törless le dice a su madre que lo cambie de institución.
La Clase (2007), de Ilmar Raag. En un colegio, la mayoría de los alumnos varones del aula le hacen bullying a uno de ellos, a Joosep; ante ello los demás se ríen y burlan. Solo Kaspar, por lealtad, decide defenderlo y se enfrenta a los agresores. El hostigamiento y la humillación se intensifican sucesivamente, esta vez contra ambos. Un día Kaspar y Joosep deciden vengarse. Joosep toma dos pistolas y un rifle de su padre. La contradicción principal se resuelve cuando, a la mañana siguiente, ambos ingresan a la cafetería del colegio y buscan a los matones para dispararles; y se inicia una masacre en la que mueren varios estudiantes.

\section{Conflicto entre los padres de familia y la escuela}

No siempre la escuela es bien vista por la sociedad, en ciertos lugares y por múltiples razones la escuela es considerada innecesaria, una pérdida de tiempo y esfuerzo para los que asisten a ella por largos años. Pero también, la escuela es vista como una institución peligrosa, puede ser subversiva, porque la información que se transmite a los alumnos puede convertirse en conocimiento, en la capacidad de conocer objetivamente los problemas de la realidad social.

El profe (1971), de Miguel M. Delgado y protagonizada por Mario Moreno "Cantinflas" y Marga López. Un profesor de escuela primaria (Cantinflas) es enviado a una escuela rural. La población lo espera aparentemente con entusiasmo, pero Don Margarito Vásquez, un miembro del grupo de poder local, expresa su desagrado. La escuela se encuentra abandonada y deteriorada. El profesor busca ayuda en la población, pero encuentra rechazo, en un inicio los alumnos no muestran mucho interés por asistir a la escuela. Sin embargo, el profesor va ganando el afecto de la mayoría de los niños y les inculca a que valoren la educación y con la asistencia de las altas autoridades se reconstruye la escuela.

Padre padrone (1977), de Paolo y Vittorio Taviani. En un poblado, un tiránico padre de familia agricultor no desea que su menor hijo Gavino asista a la escuela pues prefiere que trabaje en el campo. Como contradicción principal se grafica el enfrentamiento del padre de familia contra la escuela; y como secundario conflicto social se plasma la contraposición de dos mundos: el ruralanalfabeto y el urbano-educado. La contradicción principal se resuelve cuando Gavino decide servir en el ejército, logrando así escapar a la casi 
esclavitud impuesta por su padre. Llega a estudiar en la ciudad y años después se hace profesional con mucho éxito.

\section{Conflicto entre la escuela, padres y alumnos}

No siempre son armónicas las relaciones entre la familia, la escuela y los alumnos. Muchas familias esperan que la escuela eduque o corrijan a sus hijos $\mathrm{y}$, asimismo, muchos profesores esperan tener alumnos correctamente educados. De igual forma, los conflictos familiares casi siempre se impregnan en la conducta de los alumnos. Destacan las películas:

El Club de los Cinco (1985), de John Hughes. Cinco jóvenes (dos mujeres y tres varones), pasan juntos un sábado castigados y depositados en la biblioteca. El conflicto principal se expresa entre la escuela represiva y los indisciplinados alumnos. El castigo consiste en no hablar ni moverse de sus asientos ni dormir, deben permanecer nueve horas y redactar un ensayo en el que cada estudiante debe escribir sobre lo que él o ella cree que son. A medida que pasan las horas, los estudiantes que aparentemente no tenían nada en común, se van conociendo, afloran sus propias diferencias, revelan sus íntimos secretos y confiesan los motivos de sus castigos. Descubren que ellos tienen relaciones problemáticas con sus padres. El conflicto principal se resuelve cuando el grupo, en vez de escribir cada uno la tarea asignada, escriben una sola carta al director del colegio en donde se oponen a la petición de describir lo que son, pues se consideran injustamente etiquetados con los estereotipos que les asigna el colegio y su familia.

Matilda (1996) de Danny DeVito y protagonizada por Mara Wilson. La contradicción principal se expresa entre Matilda, una niña que se enfrenta a sus padres (de mala reputación, que detestan los estudios y no desean que ella estudie) y la tiránica directora de la escuela. Por una serie de acontecimientos ocurridos en el colegio la directora es removida del cargo y se va de la ciudad. Una joven profesora es elegida directora y realiza cambios en el colegio. La película finaliza resolviendo los dos conflictos: los padres de Matilda se van del país, huyendo de la ley por sus turbios negocios, y la joven profesora adopta a Matilda.
Los 400 golpes (1959), de François Truffaut y con la actuación de Jean-Pierre Léaud. Antoine es un adolescente incomprendido por sus padres y maestros, debido a su comportamiento rebelde. La falta de atención de su familia hace de él un alumno díscolo en el colegio, cuyas travesuras colman la paciencia de sus profesores. Un día, no asiste al colegio y se involucra en otros problemas. Al intentar robar una máquina de escribir de la oficina de su padrastro, es descubierto y termina en un reformatorio. La película es una revelación y denuncia del equívoco e injusto tratamiento de la delincuencia juvenil por parte del Estado francés en ese momento.

Estrellas en la Tierra (2007), de Aamir Khan y Amole Gupte. Ishaan, es un niño de 9 años que no cumple con las tareas que son normales entre los alumnos de su edad, como leer, escribir, sumar, atarse los pasadores, etc. Por su conducta desadaptada y su bajo rendimiento académico, su padre decide enviarlo a un colegio internado, pero Ishaan se sentirá marginado y deprimido. El conflicto que ocurre entre el colegio, el niño y sus padres, se resuelve cuando el nuevo profesor de arte descubre que Ishaan padece de dislexia e intenta ayudarle y percibe en él su oculta vocación artística. Finalmente, Ishaan llega a demostrar un gran talento en el arte, en una pública competencia de dibujo logra ganar el premio al mejor dibujo. La contradicción se resuelve positivamente, el profesor temporal es admitido en la escuela por haber logrado "corregir" al niño y los padres comprenden y aceptan las limitaciones naturales de su menor hijo.

\section{Conflicto entre la escuela y profesor}

El profesor es casi siempre incomprendido cuando, en un centro educativo en donde el conservadurismo y el tradicionalismo se imponen férreamente, éste quiere alterar el statu quo, quiere dejar "su huella", mejorando el ambiente académico con nuevos aires de libertad y creatividad. En este tipo de películas destacan:

La sociedad de los poetas muertos (1989), de Peter Weir y protagonizada por Robin Williams. A una escuela de internado llega un profesor de literatura que logra gratamente impactar a sus alumnos, originándose así el conflicto principal del filme: entre un carismático joven profesor y la 
institución educativa tradicional y conservadora. El profesor, utilizando estrategias innovadoras y creativas, hace que sus clases sean interesantes y no rutinarias, alentando a sus alumnos a "pensar por sí mismos". Esta conducta del profesor incomoda a la institución educativa y a los otros profesores. Cuatro alumnos descubren que, cuando el profesor era como ellos, formaba parte de un círculo denominado "La sociedad de los poetas muertos", que se reunían en una cueva cerca del colegio, para leer poesía que ellos escribían. Estos cuatro amigos hacen lo propio, pero son descubiertos y reciben castigos y amenazas de expulsión.

Un conflicto secundario surge cuando un alumno del grupo no solo decide actuar en una obra de teatro, sino que también desea ser actor, en contra de los deseos de su autoritario padre, quien lo recrimina y lo amenaza con sacarlo del colegio y matricularlo en una institución militar. Este conflicto secundario se resuelve cuando estando en casa el alumno toma un arma de su padre y se suicida. El conflicto se resuelve cuando el profesor es culpado injustamente del suicidio y es expulsado de la institución; los alumnos lo despiden subiéndose sobre sus carpetas como acto de rebeldía y como gesto de solidaridad.

La sonrisa de Mona Lisa (2003), de Mike Newell, con la actuación de Julia Roberts. A mediados del siglo $\mathrm{XX}$, en la coyuntura de la posguerra, una maestra de Historia del Arte, es contratada en un prestigioso colegio. La profesora consideraba que las mujeres más brillantes del país deberían tener la oportunidad de emanciparse socialmente. La tradicional política educativa del colegio era formar a los varones como exitosos empresarios ejecutivos y a las mujeres como responsables esposas y madres de familia. Aquí surge la primera contradicción entre la profesora y la escuela. Los directivos del colegio adecúan los fines educativos a esta nueva coyuntura: las mujeres dejan de trabajar en las grandes fábricas, sus puestos laborales son ocupados por varones veteranos de guerra. El conflicto principal de la película se expresa cuando la profesora es cuestionada por los directivos del colegio como subversiva, por tratar en sus clases las nuevas expresiones de la pintura contemporánea y por alentar a una alumna a seguir estudios en la universidad. La contradicción principal y el filme concluyen cuando la profesora no es contratada por el colegio y sus alumnas la despiden con muestras de cariño y tristeza.

\section{Conflicto interno o subjetivo en el alumno o en el profesor}

La población escolar, en sus niveles primarios y secundarios, es muy sensible y emotiva en el proceso de adaptación y convivencia grupal. Es frecuente que surjan en los estudiantes problemas de conducta, de identidad y de orden emocional y afectivo. La observación de los profesores es fundamental para identificar estos desajustes o trastornos, para su oportuna intervención y tratamiento o, si es grave o complejo, para derivarlo a un especialista. Lo importante es ayudar, asesorar o intervenir terapéuticamente para evitar que dicho malestar repercuta en el rendimiento escolar o en el desarrollo personal de los niños y adolescentes. En este tipo de película destacan:

El ángel azul (1930), de Josef von Sternberg y protagonizada por Emil Jannings y Marlene Dietrich. El conflicto interno que se narra en el filme se suscita en el mundo interior, en la conciencia del prestigioso y riguroso profesor, quien termina su vida agobiada por sus amorales obsesiones, seducido por los encantos de una bailarina de cabaret.

La Ola (2008), de Dennis Gansel. En un instituto para jóvenes un profesor, que imparte un seminario sobre autarquía y dictadura, decide hacer un experimento para explicar cómo es que se origina y funciona un régimen político totalitario. Para tal fin los alumnos crean una asociación que adopta como frase "fuerza mediante la comunidad", considerando que la comunidad es más importante que el individuo. En este filme el conflicto es interno, ocurre en la conciencia de los alumnos: entre las "viejas" ideas que tienen y las nuevas ideas que van internalizando conforme avanza el experimento que realiza el profesor. El individuo deja de tener sus propios pensamientos, para convertirse en una masa que puede ser controlada fácilmente. El grupo se va consolidando en unidad y disciplina, con nuevos integrantes y con conductas agresivas contra los "otros". Días después, el profesor los convoca a una asamblea en donde presentará al líder de la asociación. El fervoroso público joven espera impaciente, pero el líder no llega, frente a ellos se enciende un televisor que transmite imágenes de Hitler arengando a las masas que le seguían. Con este experimento el profesor les demostró con qué facilidad se puede caer ante las ideas del totalitarismo. 
Profesor Lazhar (2011), de Philippe Falardeau, con el protagonismo de Mohamed Fellag y Sophie Nélisse. En una escuela de Primaria en Quebec dos niños (Simon y Alice) descubren a su joven profesora ahorcada en el aula. Este hecho violento e inesperado genera el conflicto principal del filme: un gran choque traumático en el mundo interno de los niños del aula. Todas las demás contradicciones que se generan a lo largo del filme tienen su base en esta enigmática tragedia. Un migrante argelino llamado Bachir Lazhar sustituye a la profesora, quien vive a la vez un drama interno (su esposa e hijos fueron asesinados en Argelia), profesor y alumnos procesan en su mundo interno sus propios duelos con una gran tristeza y soledad, esto propicia un vínculo de identificación, comprensión $\mathrm{y}$ afectos mutuos.

\section{Conflicto externo, en el contexto en que se ubica la escuela}

La escuela no es una isla, está relacionada con un mundo que existe más allá de sus paredes, es una institución que forma parte de su entorno social e histórico, no puede desligarse de los diversos factores "externos" que gravitan sobre ella y sus integrantes. Destacan las películas:

Hoy empieza todo (1999), de Bertrand Tavernier y con la actuación de Philippe Torreton y María Pittaresi. En un pequeño pueblo minero del norte de Francia, sus habitantes están de paro a causa de la crisis de la producción minera. Daniel, es el director y profesor de la escuela infantil y sobrelleva una vida también difícil. Aparentemente, la escuela se convierte en un ámbito de felicidad en donde los niños son tratados con respeto, con igualdad y cariño; y con sus cantos, juegos y tareas escolares pueden, temporalmente, escapar de la cruda realidad que les rodea: miseria material y moral, desocupación laboral, crisis familiar, incesto, alcoholismo, abuso y maltrato familiar y desesperanza en el futuro. En este agudo conflicto la escuela, además de brindar instrucción y conocimientos, asume una responsabilidad social que consiste en promover el cambio de actitudes de las familias, de los niños que proceden de diferentes características, procurando la integración y superando las diferencias físicas, sociales y culturales, exigiendo que las autoridades asuman sus propias responsabilidades políticas. Y de esta manera tratar de mejorar la calidad de vida de la comunidad en la cual está ubicada la escuela.
La ladrona de libros (2013), de Brian Percival y con la actuación de Sophie Nélisse y Geoffrey Rush. Los hechos acontecen en 1938, en una ciudad del interior de Alemania. Liesel es una niña de 9 años que el Estado da en adopción a una familia obrera. El contexto de la historia está enmarcado en la rápida expansión de la política y propaganda Nazi a nivel nacional. En este ambiente de rigor, represión y temor que produce la nazificación, la escuela se convierte en un centro de adoctrinamiento y fanatismo. Este es el nudo del conflicto principal de la película. El día del cumpleaños de Hitler el alcalde de la ciudad convoca a un acto público en la plaza principal, en donde se organiza una gran quema de libros, cuando todos se retiran de la plaza, Liesel logra recuperar un libro. Posteriormente, este amor a la lectura la obliga a sustraer subrepticiamente ("tomar prestado" dice ella) libros de la biblioteca del alcalde de la ciudad. Terminada la guerra, la ciudad y la escuela vuelven a la normalidad.

A continuación, en la tabla 1 , se sintetiza gráficamente la taxonomía fílmica propuesta.

Tabla 1. Tipos de películas, de acuerdo con el conflicto principal del argumento.

\begin{tabular}{lll}
\hline & ARGUMENTO & PELÍCULAS \\
\hline 1 & Conflicto entre la escuela & Cero en Conducta \\
& y los alumnos & La ciudad y los perros \\
\hline 2 & Conflicto entre los & Al maestro con cariño \\
& alumnos y el profesor & $\begin{array}{l}\text { Juego de honor } \\
\text { Mentes peligrosas }\end{array}$ \\
\hline 3 & Conflicto entre los & El colegial \\
& alumnos & El joven Törless \\
& & La Clase \\
\hline 4 & Conflicto entre los padres & El profe \\
& de familia y la escuela & Padre padrone \\
\hline 5 & Conflicto entre la escuela, & Los 400 golpes \\
& los padres y los alumnos & El Club de los Cinco \\
& & Matilda \\
& & Estrella en la Tierra \\
\hline 6 & Conflicto entre la escuela & La sociedad de los \\
& y el profesor & poetas muertos \\
& & La sonrisa de Mona \\
& & Lisa \\
\hline 7 & Conflicto interno (en el & El ángel azul \\
& profesor y en el alumno) & La Ola \\
& & Profesor Lazhar \\
\hline 8 & Conflicto externo (en el & Hoy empieza todo \\
& contexto social/histórico) & La ladrona de libros \\
\hline
\end{tabular}




\section{Conclusiones}

Con el análisis crítico del mensaje, se ha establecido que, mediante la identificación del conflicto principal de las películas, se logra revelar el contenido del mensaje latente del filme.

Los productores utilizan el microcosmos de la escuela como núcleo argumental de un filme para graficar metafóricamente lo que por extensión ocurre en la sociedad: las diferencias culturales y de clase, los estereotipos y prejuicios sociales, étnicos y religiosos; así como el ejercicio del poder, la marginación, el abuso, el autoritarismo, el abandono familiar y social.

Los realizadores utilizan en sus argumentos casi siempre escuelas organizadas y dirigidas por instituciones de jerarquías administrativas verticales y conservadoras, como el ejército y la iglesia, con la finalidad de crear una atmósfera de opresión y dominio. Asimismo, optan por aquellas escuelas que tienen internado, para graficar mejor las condiciones de encierro, marginación y de castigo.

En las películas, los profesores son representados como gestores de cambios en las escuelas, unos al inicio encuentran resistencia y rechazo; en cambio otros, con imaginación y promoviendo valores éticos y humanos en el desarrollo de sus asignaturas, logran alterar el anquilosamiento institucional de las escuelas, logrando finalmente el afecto y la simpatía de sus alumnos y autoridades.

La presente propuesta taxonómica de clasificación y ordenamiento de las producciones cinematográficas referidas a la escuela como elemento protagónico permite poner en orden el creciente incremento de realizaciones fílmicas que asumen en su estructura narrativa esta compleja y diversa temática de la relación escuela y sociedad. Películas que muestran la intervención de diversos agentes protagónicos en la realidad educativa, cada uno de ellos con sus propios logros y errores, con sus específicos desafíos y responsabilidades.

La escuela como centro de la trama argumental permite a los realizadores cinematográficos (productores, guionistas, directores) considerar que esta institución no solo es o debe ser el segundo hogar en donde se forma las personas, sino también el ámbito en el cual confrontan una serie de sentimientos, conflictos, alegrías, temores $\mathrm{y}$ afectos que pueden marcar sus vidas en el futuro.

\section{Referencias bibliográficas}

Althusser, L. (1974). Ideología y Aparatos Ideológicos de Estado. Buenos Aires: Nueva visión.

Altman, R. (2000). Los géneros cinematográficos. Barcelona: Paidós.

Alves, P.; Melaré, D.; y Ceu, M. (2019). Cine, Educación y Sociedad. Icono 14. Revista de Comunicación y tecnologías emergentes, 17(2), 1-9. doi: 10.7195/ri14.v17i2.1423

Diaz, Y. E. (2012). Lectura y análisis crítico de cine. Una estrategia didáctica e innovadora para el logro de aprendizajes en el contexto universitario. Revista Docencia Universitaria, 13(1), 187-199. $\quad$ https://revistas.uis.edu. co/index.php/revistadocencia/article/ view/3267/3477

Egri, L. (2009). El arte de la escritura dramática. Fundamentos para la interpretación creativa de las motivaciones humanas. México: Centro Universitario de estudios cinematográficos. Universidad Autónoma de México.

Fernández, M. C. y López, E. (2018). Géneros y subgéneros cinematográficos. Making of. Cuaderno de cine y educación, (139), 9-13. http://www.centrocp.com/generos-ysubgeneros-cinematograficos/

Flick, U. (2007). Introducción a la investigación cualitativa. 2da. ed. Madrid: Morata.

García, F. J. (2015). Metodología crítica de análisis textual en la realización filmica. [tesis doctorado, Universidad Complutense de Madrid]. Repositorio Institucional UC. https://eprints.ucm.es/id/eprint/29486/1/ T35957.pdf

Gómez, P. J. (2005), La representación de la escuela en el cine: una metáfora del estado para las sociedades en crisis o la responsabilidad de mostrar abiertamente carencias. Comunicación y hombre. Revista Interdisciplinar de Ciencias de la Comunicación y Humanidades (1), 149163. https://www.cinemanet.info/2009/02/ la-representacion-de-la-escuela-en-el-cineuna-metafora-del-estado-para-sugerir-lascarencias-de-so/

González, J. y Valdés, J. (2018). La adolescencia como género cinematográfico: de la reivindicación a la oportunidad. Revista 
Pediatría Atención Primaria, 20(77), 19-37. https://scielo.isciii.es/scielo.php?script=sci arttext\&pid=S1139-76322018000100014

Gubern, R. (2014). Historia del cine. Barcelona: Anagrama.

Guzmán, S. (2013). PIXAR y los géneros cinematográficos. En A. Baccaro y S. Guzmán (Eds.), El cine y sus lenguajes, (pp. 90-98), Quito: Signis ALC.

Heil, C. (8 de mayo de 2011). El Conflicto. Blog Sueños de un guionista. https://blogs.ffyh. unc.edu.ar/suenosdeunguionista/? $\mathrm{p}=113$

Hernández, R.; Fernández, C. y Baptista, P. (2014). Metodología de la investigación. 6ta. ed. México: McGraw-Hill.

Horkheimer, M. y Adorno T. (1998). Dialéctica de la Ilustración. Fragmentos filosóficos. 3ra. ed. Madrid: Trotta.

Loscertales, F. (1999). Estereotipos y valores de los profesores en el cine. Una propuesta para estudiar los valores de la profesión. Revista Comunicar Revista Científica Iberoamericana de Comunicación y Educación, (12), 37-45
Martínez-Salanova, E. (2003). El valor del cine para aprender y enseñar. Revista Comunicar, Revista Científica Iberoamericana de Comunicación y Educación (20), 45-52 https://www.revistacomunicar.com/index. php? contenido $=$ detalles $\&$ numero $=20$ \&articulo=20-2003-07

Peters, J. M. L. (1961). La educación cinematográfica. UNESCO. París.

Picos, J. (2014). Las 89 películas sobre educación preferidas de los profesores. Revista UNIR. Universidad Internacional de La Rioja. http:// www.unir.net/educacion/revista/noticias/las89-peliculas-sobre-educacion-preferidas-delos-profesores/549201440259/

Zavala, L. (2013). Sobre la evolución de los géneros cinematográficos. Revista La Colmena, (80), 131-138.

Zillmann, D. (2000). The coming of media entertainment. En D. Zillmann y P. Vorderer. (Eds.), Media Entertaiment. The psychology of its appeals, (pp.1-20), NJ: Routledge. 